\title{
Laboratory Assessment of Forest Soil Respiration Affected by Wildfires under Various Environments of Russia
}

\author{
Evgeny Abakumov, ${ }^{1}$ Ekaterina Maksimova, ${ }^{1}$ Anna Tsibart, ${ }^{2}$ and George Shamilishviliy ${ }^{1}$ \\ ${ }^{1}$ Department of Applied Ecology, Saint Petersburg State University, 16th Line 29, Vasilyevsky Island, Saint Petersburg 199178, Russia \\ ${ }^{2}$ Department of Landscape Geochemistry and Soil Georgaphy, Moscow State University, Vorobyovy Gory 1, Moscow 119991, Russia \\ Correspondence should be addressed to Evgeny Abakumov; e_abakumov@mail.ru
}

Received 10 March 2017; Revised 14 June 2017; Accepted 4 July 2017; Published 13 August 2017

Academic Editor: L. M. Chu

Copyright (c) 2017 Evgeny Abakumov et al. This is an open access article distributed under the Creative Commons Attribution License, which permits unrestricted use, distribution, and reproduction in any medium, provided the original work is properly cited.

\begin{abstract}
Pyrogenic carbon emission rates were estimated in the soils of three natural zones in Russia: forest-tundra, south-taiga, and foreststeppe. Postfire soils were found to be characterized by essential losses of soil C due to the combustion fire effect. Soils lost 3 or 5 parts of initial carbon content and showed an essential decrease in the $\mathrm{C} / \mathrm{N}$ ratio during the fire effect. The $\mathrm{pH}$ values increased due to soil enrichment by ash during the fire events. $\mathrm{CO}_{2}$ emission rates were highest in natural soil samples, because the amount of organic matter affected by mineralization in those soils was higher than in natural ones. Simultaneously, the total values of mineralized carbon were higher in postfire soils because the SOM quality and composition were altered due to the fire effect. The only exception was in forest-tundra soils, where a high portion of dissolved organic compounds was released during the surface fire. The quality of initial SOM and intensity of the wildfire play the most important roles in the fate of SOM in postfire environments. Further study of $\mathrm{CO}_{2}$ emissions is needed to better characterize postfire SOM dynamics and develop an approach to model this process.
\end{abstract}

\section{Introduction}

Great attention has been paid to soil organic matter (SOM) mineralization and possible $\mathrm{CO}_{2}$ emissions from soil, due to their important effects on the global carbon cycle and ecosystem stability. Fire has an important impact on soil properties [1-13]. Soil processes in postfire soils are quite different from those in the soils of natural landscapes or in technogenous ones. After fires, there is an intensive accumulation of ash on the topsoil $[14,15]$, ash redistribution in landscapes and the leaching of nutrients and minerals into deeper horizons $[16,17]$, surface overcompaction and crust accumulation, and soil structure transformation of [4]. Nonetheless, the most expressed consequence of wildfires is uncontrolled $\mathrm{CO}_{2}$ emission due to changes in soil organic matter stability that occur in high temperatures $[18,19]$. The mass loss (i.e., gravimetric concentrations) of soil organic carbon in postfire environments is typically underestimated by researchers in terms of rates and balance units $[20,21]$.
Two main constituents of SOM loss in postfire environments are mineralization and erosion losses. The mass emission loss of organic carbon can be evaluated by field and laboratory experiments [22]. Postfire $\mathrm{CO}_{2}$ emission rates have previously been shown to be strongly related to the intensity of the fire impact $[1,22-24]$. Furthermore, the mineralization rate is affected by the type of burned organic material [9]. SOM mineralization rates are higher in burned postfire soils than in unburned ones, and alterations in organic matter in postfire soils can lead to alteration of total SOM stability $[22,25]$.

Controlled laboratory experiments provide data on possible mineralization losses from soils that face different fire impacts. Such experiments are needed to evaluate the apparent stability of SOM mineralization losses and to predict the possible stability and loss of organic carbon in the soil of postfires environments. Data obtained in controlled laboratory experiment are not comparable with data from field experiments (e.g., closed chambers method). Nevertheless, 


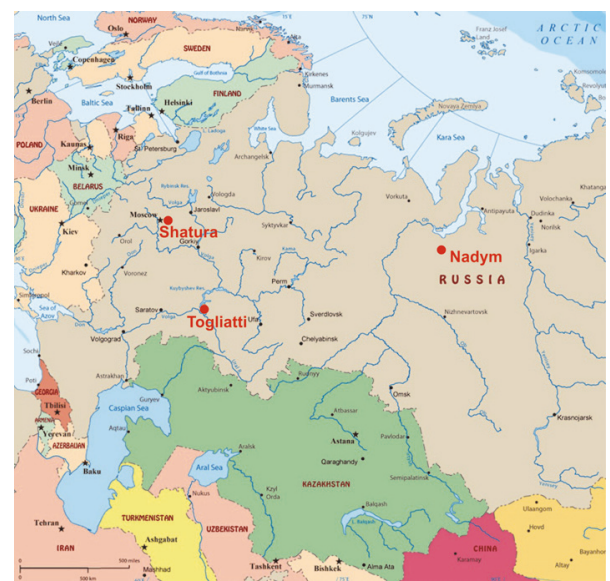

FIGURE 1: Location of study sites.

data obtained in unified conditions can be used for further simulation modeling of SOM transformation.

The aim of this study is to examine the mineralization of soil organic carbon (SOC) from different types of postfire soils from different environments in Russia, using laboratory incubation with special attention to carbon mineralization rates and $\mathrm{CO}_{2}$ emissions.

\section{Materials and Methods}

2.1. Study Sites. Three types of zonal environments (ecoregions) were selected to investigate soil properties and $\mathrm{CO}_{2}$ emission intensity: forest-tundra, south-taiga, and foreststeppe. Plots situated in the areas surrounding the cities of Nadym (N), Shatura (S), and Togliatti (T) were investigated, using the scenario of surface fires. Sampling was conducted in the one months after surface fires in 2012 ( $\mathrm{S}$ and $\mathrm{T}$ ) and in $2016(\mathrm{~N})$. The location of the sites are shown in Figure 1. The environments studied differ in terms of soil profile organization and the nature of organic matter that accumulated in the soil profiles. Nevertheless, these three plots were studied to understand SOM stabilization rates and biodegradability because there is a lack of data on the quality and alteration of SOM quality in various climatic environments and different soil horizons.

Podzols of forest-tundra were sampled from all soil horizons because of the possible redistribution of organic matter due to eluviation processes. Peatland soils from the Shatura plots were also sampled from all the horizons of solum; two types of soil horizons were studied: burned and unburned. In the case of forest-tundra and south-taiga, only the surface fire scenario was accounted for investigation. In case of forest-steppe, we only compared SOM quality in the superficial horizons (A), because solums were undeveloped and only presented by a few centimeters of humus-enriched topsoils.

2.1.1. Forest-Tundra. Recent data on the natural fire effect on polar (arctic) ecosystems were gathered between July 2016 and August 2016 in the Nadym subregion of the YamalNenets Autonomous Region, Northwest Siberia, Russian
Federation ( $\mathrm{N} 65^{\circ} 32^{\prime} 00^{\prime \prime}$; E $72^{\circ} 31^{\prime} 00^{\prime \prime}, 40-60 \mathrm{~m}$ asl). Forest fires were reported during this time period in the northeast area of the studied region. The affected territory was approximately 15,000 hectares and included the areas surrounding the Pangodi settlement (i.e., location of the compressor Pangodinkaya station, which is a key part of the Siberian gas pipeline system). The reason of the fire occurrence was the abnormal high temperatures established since the beginning of the July $\left(27-33^{\circ} \mathrm{C}\right)$. The fire arose in studied tundra-forest ecosystem was characterized by medium to high severity, which is proved by thickness of the burned litter and obtained data on the soil respiration rates in fire-affected and control soil. In accordance with the investigations in soils, subjected to fires of medium intensity, the release of carbon dioxide is larger in comparison with the control, whereas in case of strong fire this parameter is smaller than in unaffected soil. Thus the high severity of the wildfire is supposed.

According to geographical zoning assessments of the Tumensky region, the studied territory belongs to the Nadym province of tundra-forest width-zonal Champaign area [26]. From a geomorphological point of view, the studied area is characterized by a distribution of lake-alluvial terraces and represents a subhorizontal surface with absolute altitudes ranging from 30 to $60 \mathrm{~m}$. The following landscapegeomorphological complexes are well distinguished in the modern floodplain of the Nadym River: a strip of ancient above-floodplain terraces forming the base of the root bank, remnants of segmented meanders, and a modern river floodplain with active channel processes. Forest ecosystems of the territory are characterized by three periods and stages of vegetation succession on alluvium. The first stage is the primary colonization of alluvial sediments with sedges and willow that forms separate bushes and small thickets where the accumulation of alluvium continues. The second stage is a homogenous dense willow tree (up to 45 trunks per $10 \mathrm{~m}^{2}$ ) with a height of up to $4 \mathrm{~m}$, under the canopy of which there are single specimens of sedges, reed grass, and floodplain grass. The thickness of litter is small, as it is periodically overlapped by alluvial deposits applied by spring-summer spills. Serried stand is formed by willow and birch on plot related to the third stage of the first period. Here, under the canopy, there are single specimens of spruce growth with $5-10 \mathrm{~cm}$ in height, ground cover is rare, represented by reed, sedge, and horsetail, and mosses are found only in depressions of the relief.

Described area is related to the second period of succession represented by two variants of the second stage, differing in composition of the stand. On these plots, spruce (sometimes larch) forms the second tree floor of the community, and under the canopy there are many cedar and spruce undergrowth and a small number of larches. In the surveyed areas, the age of spruce and cedar was 80 to 120 years and only for single trees was about 160 years. This indicates a relatively short duration of the period of reorganization of riverine landscape complexes in the lower floodplain.

A study of the renewal potential of the main forestforming species showed that shoots and young coniferous trees appeared under the canopy of the birch and willow communities when they reached the age of 45-60 years. By 
this time, a diluted grass cover with an abundance of forest species, a litter, and a thin humus horizon of the soil had already been formed. Further, as the development of woody vegetation changes, the species composition of coniferous growth was changing correspondingly.

The landscapes of the most humid areas of the territory are characterized by the alternation of hilly permafrostaffected peat bogs (with shrub, moss, and lichen vegetation on the hillocks and sedge-cotton grass-moss vegetation in the depressions) and hummocky permafrost-affected shrublichen-moss bogs combined with hummock-hollow bogs. The landscapes of the drained areas are covered with coniferous forests containing birch and larch [26].

The burned ecosystem located by lowlands with tundraforest landscape and was characterized by low soil diversity due to the predomination of homogeneous lacustrine sand parent material and general flatness of the relief. The vegetation cover was composed of highly stratified larch-pine forest (Larix sibirica, Picea obovata, Pinus sibirica, and $P$. sylvestris) with shrubs (Ledum palustre, Empetrum nigrum, Vaccinium vitis-idaea, and V. uliginosum) and moss-lichen underbrush (Pleurozium schreberi, Hylocomium splendens, Polytrichum alpestre, Cladonia arbuscula, C. rangiferina, and C. stellaris). The pine forest ecosystems were represented by stands consisting of 10-15 trees and were surrounded by peat land cover. In this study, only soils affected by fires under the pine stands were investigated. Wildfires in Nadym area have become more frequent during last decades and ecosystems of this particular area are faced to wildfires every 5 years. The fire arose in described tundra-forest ecosystem of Nadym region was characterized by medium to high severity, which was evidenced by the thickness of the burned litter. A study of the renewal potential of the main forest-forming species showed that shoots and seedlings of coniferous trees appear under the canopy of the birch and willow communities when they reach the age of $45-60$ years. By this time, a diluted grass cover with an abundance of forest species, a litter, and a thin humus horizon of the soil have already been formed. Further, as the development of woody vegetation changes, the species composition of coniferous growth was changing correspondingly.

The soil cover of the investigated area is characterized by a complex mosaic of Podzols that belong to drained sandy positions and Histosols formed in swampy hollows [27]. Gleysols and Cryosols are also typical for the described territory, especially to sites with presence of permafrost, causing stagnic, moisture conditions. The soil is characterized by a sandy texture and represents a Podzol with well-expressed spodic horizons of yellow-ocherous tones underlying albic horizons that were affected by the fire.

2.1.2. South-Taiga. The research was conducted in the West Meshchera fluvioglacial plain of the Moscow Region (Shatura District, $\mathrm{N} 55^{\circ} 39$, E $39^{\circ} 36^{\prime}, 120 \mathrm{~m}$ asl). The investigated area is covered by peatlands and lies on ancient alluvial deposits $[16,17]$. This plot belongs to the Petrovsko-Kobelevskoe highmoor peat, which is a part of the Shatura wetland area. Its total area is 6,443 ha. Prior to peat extraction, the peat layer was found to be $7.5 \mathrm{~m}$ and its average thickness was $2.5-4.0 \mathrm{~m}$ [18].
The large areas of the study site were transformed by drainage and peat mining. Mining began in the peat deposits of the Shatura district in the 1920s [28]. Nowadays the excavation has stopped and the most of peat-hags are in a renewal stage [29]. Because of peat excavation, the natural bog complex changed to large open pits, which were connected with the numerous channels and distributaries and the fields of peat mining at different stages of exploitation. The birch-aspen forests (Betula pendula Roth. and Populus tremula L.) grow on banks. These types of tree stands were selected for sampling of postfire soils and mature soils. Because of changes in the hydrological regime, the number of peat fires and areas impacted by peat fires increased dramatically [29]. Zonov and Konstantinovitch [30] identified a repeating pattern of fires in drained peatlands, whereby large fires occur nearly every 10 years (i.e., 1972, 1982, 1992, and 2002). In 2010 the wildfires in Russia damaged large areas, and in the Moscow region they caused significant air pollution and ecosystem degradation [31-33]. The Gleyic Histosols, Histic Podzols, and Sod Podzols [34] represent the soil cover of the studied area. This work investigates the peat soils affected by the fires of 2002, 2010, and 2012. The field work and sampling procedures were both conducted in 2012. Histosols and Histic Podzols represent mature soils. The Histosols have the following soil horizons: O-H-Hp-He-Ha-C. The typical soil profile of the Histic Podzols is O-A-E-EBhs-Bhs-Cs. After the fires smoldered and burned out the peat horizon, new ash horizons (Cpir) formed up to $5 \mathrm{~cm}$ deep; they formed over peat charry horizons (Hpir, $2-3 \mathrm{~cm}$ ) and pyrogenic muck peat horizons (Ha,pir, 2-3 cm). Soils under the birch-aspen tree stands were sampled for further laboratory analyses.

2.1.3. Forest-Steppe. The study was conducted in the Samara region near the Volga River, in the central part of European Russia (N 58 $39^{\prime} 44^{\prime \prime}$; E $39^{\circ} 17^{\prime} 48,179 \mathrm{~m}$ asl). The extreme summer temperatures in Russia that occurred in 2010 played a large role in the emergence of these wildfires. The extreme weather started in the middle of July and expanded to all of European Russian Europe, Ukraine, and Eastern Europe. Ultimately, the extreme heat led to drought and wildfires in the vast territories of European and Siberian Russia. The forest fire in question occurred in 2010 and affected more than 8,000 hectares. The fire severity was very high according to one of the most applied methods of identifying fire severity (that is the ash colour and ash $\mathrm{CaCO}_{3}$ content $[12,13]$ ).

The study plots were the so-called "steppe islands of pine forests" near Togljatty city, Samara region, and were exposed to widespread forest fires in 2010. It is necessary to emphasize that these "steppe islands of pine forests" are very important parts of forest-steppe ecosystems which conserve the boreal species of plants and animals as well as some soils which are untypical for a steppe zone.

The parent material is composed of old (Pleistocene) alluvial-dune landscape. A forest-steppe environment with higher pedodiversity characterizes the affected ecosystem. The vegetation is composed of pine forests Pinus sylvestris L. and other xerophytes species (Veronica spicata L., Sedum acre L., Antennaria dioica L., Calamagrostis epigeios (L.) Roth., and Centaurea marschalliana Spreng). Hardwoods (Quercus 
robur L., Betula pendula Roth., and Populus tremula L.) form one or two synfoliums and are added to a pine forest in more humid conditions. Woody and shrubby plantations were burned out, and the trunks of trees were charred to different extents in fire-affected areas. These charred trees were cut down or remained uncleaned for 1-2 years after the wildfires. The grassy cover of the postfire plots was formed by rhizomatous and loose-bunch gramen: Bromus inermis Leyss., Elytrigia repens L., Poa spp., and Agrostis canina L. The plants forming the lower forest synfolium (a shrubby, grassy, and mossy cover) burn down in case of surface fire, which indicates a surface fire. The crown fire covers the entire forest from the soil surface to the tops of tree crowns or passes through the trees and the underbrush, herbage, and moss layer. Fruits and seeds which are on the surface and in the solum (the upper soil horizons) can avoid the influence of the fire. Therefore, a crown fire is a type of surface and crown fire.

There is gramineous and herb succession stage at crown forest fire plot. The foliage cover was $60-70 \%$. The following species of plants were presented at that plot: Calamagrostis epigejos (L.) Roth., Bromopsis inermis (Leyss.) Holub, Artemisia absinthium L., Artemisia austriaca Jacq., Artemisia campestris L., Nonea pulla (L.) DC., Sisymbrium loeselii L., and Chamaecytisus ruthenicus (Fisch. ex Wolosz.) Klask. A shrub steppe will be forming at surface forest fire plot. The foliage cover is $90-95 \%$. The following species of plants were presented at that plot: Chamaecytisus ruthenicus (Fisch. ex Wolosz.) Klask., Veronica chamaedrys L., Taraxacum officinale Wigg. s.l., Saponaria officinalis L., Berteroa incana (L.) DC., and Calamagrostis epigejos (L.) Roth.

A variety of Luvisols and Chernozems prevail in the watershed [35-39]. The soil of the investigated area is sandy and sandy loam textured. In the studied area, the soil was classified as sandy loam soil on Late Pleistocene alluvial Volga sands [35], and it has weak features of alluvial phenomena without the formation of separate horizons. This soil was classified as Eutric Fluvic Arenosols with weak features of illuviation process development and sand and clay contents of $70.5-86.4 \%$ and $0.3-2.6 \%$, respectively. The plots were selected for sampling: mature plot with developed old pine forest, crown fire plot where dead pine trees were cut and removed from the plot, and surface fire plot with accumulation of wood remnants on the soil surface. This pine stand was not faced to fires during previous 150 years, and wildfire has appeared for the first time in 2010. Sampling was conducted for plots, situated on the dune hills with flat relief without expressed mesoforms $[8,10,11]$.

2.2. Laboratory Analyses. All chemical and biological parameters were determined using a fine earth of soil that had been ground and then sifted through a $2 \mathrm{~mm}$ sieve. Routine soil analyses (i.e., $\mathrm{pH}, \mathrm{C}$, and $\mathrm{N}$ ) were conducted according to standard procedures: $\mathrm{C}$ and $\mathrm{N}$ were determined using a C-H$\mathrm{N}$ analyzer, and $\mathrm{pH}$ was measured using a soil to water ratio of $1: 25$ [40]. The mineralization experiment was conducted with controlled laboratory incubation, using plastic cylinders with a diameter of $10 \mathrm{~cm}$ and a height of $20 \mathrm{~cm}$. During controlled laboratory incubation, $10 \mathrm{~g}$ of mineral soil and $5 \mathrm{~g}$ of organic fine earth were put into a cylinder. The experiment was conducted in five replications for every soil horizon (they were collected from polypedons with the square $2 \times$ $2 \mathrm{~m}$ ). The cylinders were then put in a beaker that had a water table that was close to the bottom of the soil, so as to simulate the field conditions of paddy (i.e., approximately $60 \%$ of water-holding capacity). The water content (\%) was controlled during soil incubation. $\mathrm{CO}_{2}$ emission values were determined using the protocol outlined by Anderson [41]: aliquots $(5 \mathrm{~g})$ of fresh soil were adjusted to a moisture content that was $60 \%$ of the water-holding capacity and were then incubated at $20^{\circ} \mathrm{C}$ in sealed plastic bottles with $1 \mathrm{M} \mathrm{NaOH}$. The amount of $\mathrm{CO}_{2}$ trapped in the alkaline solution was measured using titration after 7 days of incubation. In total, the incubation was conducted for 112 days. The experiment was performed in analytical triplicates. For the Nadym and Shatura samples, only the scenario of surface fire was used for comparison of burned and unaffected soil samples. For the Shatura samples, the pyrogenically affected materials (i.e., Cpir and $\mathrm{T}$ pir) were compared with deeper horizons of unaffected solum (T). For the Togliatti plots samples, the soil presented weak Arenosols with undeveloped profile. Thus, the sampling design for Shatura and Togliatti differed from the Nadym and Shatura samples, and only the superficial soil horizons in case of Togliatti were sampled for further analyses.

2.3. Statistic. The normal distribution of the data was verified previously, and analysis of variance (ANOVA) and a post hoc test were conducted. Differences were considered significant at $p<0.05$. Only superficial horizons of burned and unburned soils were examined with the use of post hoc test (Fisher's least significant difference).

\section{Results}

3.1. General Soil Properties. The soils from the Nadym plot differ from each other in terms of its $\mathrm{C}$ and $\mathrm{N}$ content (Table 1). The $\mathrm{C}$ content decreased due to the impact of the fire on the topsoil horizon. This alteration can be related directly to the combustion effect. An accumulation of organic matter of illuviation origin in the Epir soil horizon was also observed. This accumulation is confirmed by both the increased concentration of total organic carbon (TOC) compared with mature soil samples and the extended $\mathrm{C} / \mathrm{N}$ ratio in this horizon, which might be result of dissolved low molecular compounds of illuviation. Fire-affected soil samples showed small increases in $\mathrm{pH}$ values, which is typical for these types of impacted soils.

The TOC content in the Shatura plots showed greater concentrations in the mature soil samples (S12) than in the topsoil horizons, which were affected by fire (i.e., S10, S11, and S13). The decreasing TOC content is the topsoils recognized alteration of soil under the surface fire. The $\mathrm{C} / \mathrm{N}$ ratio changes were the most pronounced in postfire soils. These ratios were 4 or 5 times lower in fire-affected soil samples than in the control. The greatest change in $\mathrm{C} / \mathrm{N}$ ratios was seen in the $\mathrm{C}$ pir and Tpir horizons of the fire-affected soil samples. In contrast, the lowest $\mathrm{T}$ horizon, namely, those unaffected by fires, had $\mathrm{C} / \mathrm{N}$ values that were comparable to those of mature 
TABLE 1: General soil properties.

\begin{tabular}{|c|c|c|c|c|c|}
\hline Plot, depth, cm & C, $\%$ & $\mathrm{~N}, \%$ & $\mathrm{C} / \mathrm{N}$ & $\mathrm{pH}_{\mathrm{H} 2 \mathrm{O}}$ & Color, Munsell color chart \\
\hline \multicolumn{6}{|c|}{ Nadym surface fire } \\
\hline O ash, $0-10$ & $8,03 \pm 0,93$ & $0,51 \pm 0,02$ & 15.74 & 4,79 & $10 \mathrm{YR} 4 / 2$ \\
\hline Epir, 10-17 & $1,30 \pm 0,23$ & $0,06 \pm 0,03$ & 21.66 & 5,02 & $10 \mathrm{YR} 4 / 1$ \\
\hline BF, 17-26 & $1,20 \pm 0,25$ & $0,06 \pm 0,01$ & 20.00 & 5,21 & 7,5 YR 4/6 \\
\hline $\mathrm{BC}, 26-45$ & $1,25 \pm 0,32$ & $0.05 \pm 0,01$ & 25.00 & 4,98 & 10,5 YR 5/8 \\
\hline \multicolumn{6}{|c|}{ Nadym mature soil } \\
\hline OT, 0-10 & $13,83 \pm 0,98$ & $0,62 \pm 0,05$ & 22.30 & 4,22 & $10 \mathrm{YR} 5 / 6$ \\
\hline E, $10-18$ & $0,26 \pm 0,09$ & $0,02 \pm 0,01$ & 8.67 & 4,37 & $10 \mathrm{YR} 6 / 3$ \\
\hline BF, 18-27 & $1,47 \pm 0,05$ & $0,09 \pm 0,01$ & 16.33 & 4,71 & $7,5 \mathrm{YR} 4 / 6$ \\
\hline $\mathrm{BC}, 27-36$ & $0,40 \pm 0,05$ & $0,03 \pm 0,01$ & 13.33 & 5,03 & 10,5 YR 5/8 \\
\hline \multicolumn{6}{|c|}{ Shatura 10} \\
\hline W, $0-5$ & $6,90 \pm 0,45$ & $0.18 \pm 0,02$ & 39.33 & 6,7 & $10 \mathrm{YR} 4 / 4$ \\
\hline Cpir, 5-12 & $6,10 \pm 0,67$ & $0.78 \pm 0,03$ & 7.82 & 7,4 & $10 \mathrm{YR} 4 / 2$ \\
\hline Tpir, $12-40$ & $24,50 \pm 0,78$ & $1.78 \pm 0,05$ & 13.76 & 6,1 & 2,5 YR 2,5/1 \\
\hline $\mathrm{T}, 40-50$ & $36,79 \pm 0,24$ & $0.99 \pm 0,05$ & 37.61 & 5,2 & 10 YR 3/1 \\
\hline \multicolumn{6}{|c|}{ Shatura 11} \\
\hline Cpir, 0-10 & $2,73 \pm 0,15$ & $0.56 \pm 00,3$ & 4.87 & 7,4 & $10 \mathrm{YR} 4 / 2$ \\
\hline Tpir, 10-15 & $10,5 \pm 0,12$ & $1.12 \pm 0,07$ & 9.37 & 5,7 & 2,5 YR 2,5/1 \\
\hline $\mathrm{T}, 15-30$ & $25,3 \pm 0,67$ & $0.98 \pm 0,08$ & 25.81 & 5,3 & 10 YR 3/1 \\
\hline \multicolumn{6}{|c|}{ Shatura 12, mature soil } \\
\hline Mature T, 0-10 & $35,40 \pm 1,23$ & $0.63 \pm 0,02$ & 56.19 & 7,8 & $10 \mathrm{YR} 3 / 1$ \\
\hline Mature T, 10-20 & $28,11 \pm 0,54$ & $0.78 \pm 0,03$ & 36.02 & 8,4 & $10 \mathrm{YR} 3 / 1$ \\
\hline \multicolumn{6}{|c|}{ Shatura 13} \\
\hline Cpir, 0-10 & $5,03 \pm 0,21$ & $0.65 \pm 00,4$ & 7,73 & 7,5 & $10 \mathrm{YR} 4 / 2$ \\
\hline Tpir, 10-20 & $11,5 \pm 0,45$ & $1.05 \pm 0,09$ & 10,95 & 6,6 & 2,5 YR 2,5/1 \\
\hline $\mathrm{T}, 20-30$ & $24,53 \pm 0,65$ & $1.23 \pm 0,11$ & 19,94 & 6,5 & $10 \mathrm{YR} 3 / 1$ \\
\hline \multicolumn{6}{|c|}{ Togliatti } \\
\hline Crone fire, $0-15$ & $2,94 \pm 0,23$ & $0,57 \pm 0,06$ & 5,16 & 7,5 & $10 \mathrm{YR} 3 / 2$ \\
\hline Surface fire, $0-15$ & $2.58 \pm 0,25$ & $0,40 \pm 0,03$ & 6,45 & 6,4 & $10 \mathrm{YR} 3 / 2$ \\
\hline Mature soil, 0-15 & $16.64 \pm 0,88$ & $1,36 \pm 0,12$ & 12,23 & 6,5 & $10 \mathrm{YR} 4 / 2$ \\
\hline
\end{tabular}

soil samples. The Shatura soil samples showed increasing $\mathrm{pH}$ values under fire effect.

The SOM content in the crown fire ash of the Togliatti plot was less than that observed in the surface fire ash. A similar trend was observed in the humus pyrogenic horizons: the crown fire carbon content was $1.21 \pm 0.50 \%$ and the surface fire sample was $1.42 \pm 0.31 \%$. Thus, more intensive organic matter losses occurred as a result of crown fire where there is a complete burning of forest vegetation. As for the mineral horizons, the carbon content was generally comparable to similar indicators in the control plots. High temperatures had little impact on the mineral horizons due to the very low thermal conductivity of the litter. Thus, a carbon loss in the surface soil horizons was observed due to the destruction of organic horizons, the mineralization of root residues, and the nearly complete absence of new litter that would serve as material for humification. The $\mathrm{C} / \mathrm{N}$ ratio suggests that humification processes were more prevalent than mineralization processes in the control plot. The $\mathrm{C} / \mathrm{N}$ ratio decreased twofold in the postpyrogenic plots, due to the fact that high temperatures induced the mineralization of organic residues.

3.2. $\mathrm{CO}_{2}$ Mineralization Rates. Data from the Nadym plots (Table 2) showed higher weekly mineralization rates in the topsoil of mature soil than in postfire soil. In contrast, mineralization rates were higher in all of the mineral horizons of the postfire soil than in the unaltered ones. This can be caused by the movement of dissolved organic material down the soil profile and further by the mineralization of SOM in these soil horizons. The differences between organic topsoils of burned and unburned soils were statistically significant $(p<0.05)$.

In the Shatura plots, the highest weekly mineralization rates were observed in the topsoil of mature plots, and this rate decreased rapidly within the time period observed. In the case of the postfire plots, the highest mineralization rates were typically observed in lower $\mathrm{T}$ (Hisitc) horizons that were unaffected by the fire. This was common for the lowest horizons of T-unaffected soils and the topsoils 
TABLE 2: Average $\mathrm{CO}_{2}$ emission rates, $\mathrm{mg} \mathrm{CO} / 100 \mathrm{~g}$ soil/day.

\begin{tabular}{|c|c|c|c|c|c|}
\hline Plot & $1-3$ & $4-6$ & $7-9$ & $10-13$ & $14-16$ \\
\hline \multicolumn{6}{|l|}{ Nadym surface fire } \\
\hline $\mathrm{O}$ ash & 109,23 & 76,67 & 67,21 & 58,24 & 58,73 \\
\hline Epir & 19,20 & 20,34 & 22,82 & 25,98 & 18,78 \\
\hline BF1 & 20,40 & 32,17 & 24,41 & 20,16 & 21,97 \\
\hline $\mathrm{BF} 2$ & 45,64 & 38,64 & 38,70 & 37,36 & 12,53 \\
\hline BF3 & 33,82 & 33,77 & 34,95 & 30,86 & 21,99 \\
\hline $\mathrm{BC}$ & 27,62 & 27,73 & 37,75 & 32,96 & 25,11 \\
\hline $\mathrm{C}$ & 29,83 & 24,25 & 33,75 & 31,76 & 18,77 \\
\hline \multicolumn{6}{|l|}{ Nadym mature soil } \\
\hline OT & 421,28 & 306,64 & 403,25 & 451,81 & 341,58 \\
\hline $\mathrm{E}$ & 17,80 & 24,471 & 34,363 & 35,92 & 21,86 \\
\hline $\mathrm{BF}$ & 47,01 & 38,82 & 39,08 & 43,15 & 34,39 \\
\hline $\mathrm{BC}$ & 26,58 & 34,14 & 31,88 & 34,25 & 15,64 \\
\hline \multicolumn{6}{|l|}{ Shatura 10} \\
\hline $\mathrm{W}$ & 151,15 & 146,32 & 144,16 & 255,21 & 242,19 \\
\hline Cpir & 222,40 & 204,92 & 180,09 & 164,23 & 119,44 \\
\hline Tpir & 193,71 & 171,48 & 181,93 & 175,48 & 170,31 \\
\hline $\mathrm{T}$ & 246,87 & 134,78 & 152,08 & 127,23 & 111,33 \\
\hline Shatura 11 & & & & 0 & \\
\hline Cpir & 108,05 & 66,53 & 75,41 & 83,70 & 58,70 \\
\hline Tpir & 70,35 & 51,66 & 44,79 & 52,37 & 47,61 \\
\hline $\mathrm{T}$ & 139,10 & 68,93 & 59,92 & 36,24 & 49,41 \\
\hline Shatura 12 , mature soil & & & & 0 & \\
\hline Mature T & 400,35 & 274,57 & 289,02 & 289,02 & 269,75 \\
\hline Mature T & 253,25 & 150,25 & 158,87 & 178,08 & 165,52 \\
\hline Shatura 13 & & & & 0 & \\
\hline Cpir & 106,81 & 64,32 & 82,50 & 94,46 & 67,12 \\
\hline Tpir & 181,91 & 131,55 & 140,78 & 193,57 & 123,18 \\
\hline $\mathrm{T}$ & 326,95 & 231,79 & 261,17 & 261,17 & 239,41 \\
\hline Togliatti & 0 & 0 & 0 & 0 & \\
\hline Crone fire & 44,41 & 30,11 & 33,91 & 28,04 & 15,71 \\
\hline Surface fire & 40,80 & 29,82 & 33,35 & 28,87 & 18,83 \\
\hline Mature soil & 63,37 & 40,85 & 40,96 & 35,90 & 28,28 \\
\hline
\end{tabular}

Post hoc test Nadym surface, Nadym mature: $p<0,05$; post hoc test Shatura Mature, Shatura 10: $p<0,03$; post hoc test Shatura Mature, Shatura 11: $p<0,03$; post hoc test Shatura mature, Shatura 13: $p<0,03$; post hoc test Togliatti, Crone-Mature: $p<0,04$; post hoc test Togliatti, Surface-Mature: $p<0,04$.

of mature soils. Fire-affected horizons (i.e., Cpir and Tpir) showed gradually decreasing mineralization rates within the experiment period. The post hoc test showed essential differences between topsoil horizons of mature and forest fire-affected plots $(p<0.03)$.

The topsoil samples of the Togliatti plots showed essential differences $(p<0.05)$ in weekly mineralization rates if one compare natural soil with both fires affected (surface and crown).

3.3. $\mathrm{CO}_{2}$ Emission and SOM Stability to Mineralization. Data on TOC mineralization rates (Table 3 ) show that the total amount of $\mathrm{CO}_{2}$ evolved from the soil samples decreased with time. This trend is more pronounced for topsoil horizons than for lower organomineral ones. If we compare the amount of $\mathrm{CO}_{2}$ evolved from topsoil samples of postfire Nadym plots with those from mature Nadym soil samples, we can see that mature soil provides more intensive mineralization than postfire soil, but that this emission remains steady over the time. The potential for TOC mineralization is higher in mature topsoil than in the topsoil of fire-affected soil. This is caused by the direct fire effect. The SOM of postfire soil is initially more destroyed before the incubation experiment, while the organic matter of mature soil is initially stable and presents the unit system of the natural origin. Thus, the soil organic matter of the surface postfire soil of the Nadym plots is more stable to mineralization, because the most decomposable fractions of soil organic matter were removed by combustion during the fire event. In the mineral horizons of postfire soils the mineralization rate is lower than that of the same horizons for natural soil profiles that are situated nearby. The differences between $\mathrm{C}-\mathrm{CO}_{2} / \mathrm{TOC}$ 
TABLE 3: Portions of $\mathrm{C}$ mineralized on weeks and portion of total minerlized carbon to TOC content.

\begin{tabular}{|c|c|c|c|c|c|c|c|}
\hline \multirow{2}{*}{ Plot, horizons } & \multirow{2}{*}{ Depth, cm } & \multicolumn{5}{|c|}{$\mathrm{C}$ mineralized, gC- $\mathrm{CO}_{2} / \mathrm{kg}$ soil fine earth, weeks } & \multirow{2}{*}{$\% \mathrm{C}-\mathrm{CO}_{2} / \mathrm{TOC}$} \\
\hline & & $1-3$ & $4-6$ & $7-9$ & $10-13$ & $14-16$ & \\
\hline \multicolumn{8}{|c|}{ Nadym surface fire } \\
\hline $\mathrm{O}$ ash & $0-3$ & 6,26 & 4,39 & 3,85 & 3,95 & 3,19 & 26,99 \\
\hline Epir & $3-10(20)$ & 1,10 & 1,16 & 1,30 & 1,34 & 1,37 & 57,26 \\
\hline $\mathrm{BF} 1$ & $10-20(25)$ & 1,17 & 1,84 & 1,40 & 1,24 & 1,13 & 55,29 \\
\hline $\mathrm{BF} 2$ & $25-40$ & 2,61 & 2,21 & 2,22 & 2,00 & 1,69 & 86.08 \\
\hline $\mathrm{BF} 3$ & $40-50$ & 1,94 & 1,93 & 2,00 & 2,15 & 1,37 & 84,05 \\
\hline \multicolumn{8}{|c|}{ Nadym mature soil } \\
\hline OT & $0-20$ & 24,17 & 17,59 & 23,13 & 29,05 & 19,83 & 82,28 \\
\hline $\mathrm{E}$ & $20-30$ & 1,02 & 1,40 & 1,97 & 2,15 & 1,66 & 70,81 \\
\hline $\mathrm{BF}$ & $30-50$ & 2,69 & 2,22 & 2,24 & 2,51 & 2,04 & 79,81 \\
\hline $\mathrm{BC}$ & $50-70$ & 1,52 & 1,99 & 1,82 & 2,06 & 1,31 & 86,99 \\
\hline \multicolumn{8}{|c|}{ Shatura 10} \\
\hline W & $0-1(3)$ & 8,67 & 7,72 & 8,71 & 11,02 & 14,03 & 72,71 \\
\hline Cpir & $1(3)-3(4)$ & 12,76 & 10,27 & 11,17 & 10,27 & 9,42 & 88,39 \\
\hline Tpir & $3(4)-5(7)$ & 11,11 & 9,18 & 11,93 & 9,47 & 9,77 & 21,01 \\
\hline $\mathrm{T}$ & 7-18 & 14,16 & 6,69 & 9,47 & 8,82 & 6,38 & 12,37 \\
\hline \multicolumn{8}{|c|}{ Shatura 11} \\
\hline Cpir & $0,5-2(4)$ & 6,20 & 2,99 & 4,62 & 5,23 & 3,92 & 89,8 \\
\hline Tpir & $2(4)-7$ & 4,03 & 2,55 & 3,46 & 2,82 & 2,45 & 14,60 \\
\hline $\mathrm{T}$ & 7-8 & 7,98 & 4,34 & 3,33 & 3,49 & 1,70 & 8,24 \\
\hline \multicolumn{8}{|c|}{ Shatura 12, mature soil } \\
\hline $\mathrm{T}$ & $0-5$ & 22,97 & 13,26 & 18,97 & 16,39 & 16,21 & 24,81 \\
\hline $\mathrm{T}$ & $5-10$ & 14,53 & 7,53 & 10,83 & 8,66 & 9,99 & 18,35 \\
\hline \multicolumn{8}{|c|}{ Shatura 13} \\
\hline Cpir & $0-3$ & 6,12 & 3,42 & 4,52 & 5,13 & 4,84 & 47,84 \\
\hline Tpir & $3-5(6)$ & 10,43 & 6,05 & 9,05 & 10,09 & 9,08 & 38,88 \\
\hline $\mathrm{T}$ & $7(9)-15$ & 18,75 & 12,48 & 14,81 & 16,23 & 13,73 & 30,99 \\
\hline \multicolumn{8}{|c|}{ Togliatti } \\
\hline Crone fire & $0-4$ & 2,54 & 1,72 & 1,94 & 1,96 & 1,13 & 31,70 \\
\hline Surface fire & $0-3$ & 2,34 & 1,71 & 1,91 & 1,77 & 1,35 & 35,25 \\
\hline Mature soil & $0-4$ & 3,63 & 2,34 & 2,35 & 1,90 & 2,03 & 7,37 \\
\hline
\end{tabular}

Post hoc test Nadym surface, Nadym mature: $p<0,05$; post hoc test Shatura Mature, Shatura 10: $p<0,04$; post hoc test Shatura Mature, Shatura 11: $p<0,04$; post hoc test Shatura mature, Shatura 13: $p<0,04$; post hoc test Togliatti, Crone-Mature: $p<0,05$; post hoc test Togliatti, Surface-Mature: $p<0,05$.

values were statistically significant for the Oash and Ot topsoil (burned and unburned) horizons for Nadym plot $(p<$ 0.05).

Data from the Shatura soil samples showed a general trend of declining $\mathrm{CO}_{2}$ weekly evolving rates, with the exception of the topsoil of Shatura 10 soil. In general, weekly amount of evolving was higher in mature soil samples if the data were expressed in $\mathrm{g} / \mathrm{kg}$ of fine earth $(p<0.05, p<0.04$ and $p<0.04$ for pare comparison of topsoils of mature soil with Shatura 10, Shatura 11, and Shatura 13 soils correspondingly). But if one compares $\mathrm{C}-\mathrm{CO}_{2} / \mathrm{TOC}$ in percentages to initial TOC, then the organic horizons of postfire soil samples provide higher mineralization losses than unaffected soil. Within the soil profiles of the investigated soils, this trend of decreasing rates was observed in all 3 postfire locations. This overall trend indicates that the SOM of upper organic horizons has been altered, as expressed by the decrease in sustainability of organic matter to mineralization. This is the direct effect of fire on SOM quality and stability.

The Togliatti plot soil samples also showed this trend of decreasing of weekly evolved amount of $\mathrm{CO}_{2}$ during the experiment. The weekly evolved amounts, expressed in $\mathrm{g} / \mathrm{kg}$ of fine earth, were higher in mature soil samples than in fire-affected ones. The $\mathrm{C}-\mathrm{CO}_{2} / \mathrm{TOC}$ values were significantly high when comparing mature plot topsoil with soil from both crown and surface fires $(p<0.05)$. This difference is caused by higher initial TOC levels in mature soil that were present before the incubation experiment.

\section{Discussion}

Soil samples from three regions that were affected by fires showed essential differences in their general chemical properties. Firstly, there were essential changes in TOC content 
due to the combustion effect. The postfire soil samples are characterized by decreased TOC content and increased Nitrogen content, which in turn decreased the $\mathrm{C} / \mathrm{N}$ ratio compared to unaffected soil. Furthermore, the $\mathrm{pH}$ values increased relative to unaffected soil due to the accumulation of ash compounds [42-46].

The total amount of initial TOC that was present before the incubation experiment played a significant role in the mineralization rate. Thus, the sum of evolved $\mathrm{CO}_{2}$ was higher in those horizons that were unaffected by fire. This finding corresponds to data of Michelloti and Miesel [9], who showed that control samples provide higher $\mathrm{CO}_{2}$ emissions than those amended with postfire remnants. At the same time the portion of TOC mineralized during the experiment, expressed in percentages, was lower in topsoil samples and the lowest horizons of unaffected soils than in firealtered materials. This finding corresponds with the data of Maksimova and Abakumov [8], who showed that there is an essential alteration of organic matter quality in postfire soil. Previously it was shown that the aromaticity of soil affected by fire increases, due to declining concentrations of carboxylic and aliphatic compounds $[6,8]$. This can affect the difference in mineralization rates of the SOM in postfire and mature soils. Thus, structural changes in SOM systems play an essential role in stabilizing SOM for postfire soil [47], and the degree of SOM oxidation regulates the mineralization rates and other indexes of postfire SOM quality $[1,8]$. Comparing the zonal trend of organic matter stability to mineralization, we can conclude that the most stabilized organic matter is found in forest-steppe mature and postfire environments, where the degree of humification and TOM transformation is highest within the ecoregion sequence. The soil of forest-tundra environments is characterized by the highest alteration in organic matter and decreased sustainability of mineralization because of initial quality of SOM, as was previously substantiated [47] for polar ecosystems. Namely, the aliphatic compounds and dissolved organic carbons that experience fire events mineralize immediately or during the first 3 weeks $[1,8]$ and prevail in polar soils. In any case, the drought frequency increases in Polar and Siberian landscapes, and further estimates of SOM quality and its stability to mineralization processes should be provided in the near future. The Russian peatlands play a critical role in the formation of global and regional storages of carbon dioxide; thus the organic matter stabilization rates and possible risk of $\mathrm{C}$ pools huge losses from soil due to wildfires should be precisely estimated [48-51]. In this context, the data obtained for the Shatura south-taiga peatlands provide essential information about SOM alteration during the fire effect. It was shown that fire leads to the destabilization of peat material, which results in increased mineralization rates. In contrast, the unaffected topsoil and lowest horizons showed little mineralization activity, which indicates the essential stabilization rate of SOM in the peatlands. Our data corresponds well with those of Zhao et al. [22], who showed that mineralization rates in peatland soils increase immediately after fire events. Finally, our findings suggest that additional laboratory incubation experiments are needed for various Russian postfire environments, with the aim of specifying the role of SOM origins, quality, and soil type on SOM stabilization rates and to better understand possible postfire mineralization risks.

\section{Conclusions}

The soil processes in postfire soils differed from those in the soils of natural landscapes. After the fire event, there were (1) an intensive accumulation of ash on the topsoil, (2) SOM alteration, and (3) mineralization. Soil C emission rates were estimated in the soil of three ecoregions of Russia: foresttundra (Nadym city, Yamal Region), south-taiga (Shatura city, Moscow region), and forest-steppe (Togliatti city, Samara region). Our findings demonstrated that postfire soil was characterized by the essential loss of soil carbon, due to the burning fire effect. In our samples, soil lost 3 or 5 of initial $\mathrm{C}$ content, decreased $\mathrm{C} / \mathrm{N}$ ratios, and increased $\mathrm{pH}$ values during the fire effect. The $\mathrm{CO}_{2}$ emission rates were highest in the natural soil samples, because the amount of organic matter faced to mineralization in those soils is higher than in natural ones. The total values of mineralized $\mathrm{C}$ were higher in postfire soil samples because the SOM quality and composition were altered due to fire effect; SOM destruction under the fire effect results in decreasing of organic matter stability. The quality of initial SOM and type of the wildfire both play important roles in the fate of SOM in postfire environments. Thus, further study of $\mathrm{CO}_{2}$ emissions is needed, with the aim of better characterizing postfire SOM dynamics creating an approach to model this process.

\section{Conflicts of Interest}

The authors declare that there are no conflicts of interest regarding the publication of this paper.

\section{Acknowledgments}

This work was partially supported by the Russian Foundation for Basic Research, Projects nos. 15-34-20844 and 16-3460010.

\section{References}

[1] G. Certini, "Effects of fire on properties of forest soils: a review," Oecologia, vol. 143, no. 1, pp. 1-10, 2005.

[2] G. Certini, "Fire as a soil-forming factor," $A M B I O$, vol. 43, no. 2, pp. 191-195, 2014.

[3] R. Guénon and R. Gros, "Frequent-wildfires with shortened time-since-fire affect soil microbial functional stability to drying and rewetting events," Soil Biology and Biochemistry, vol. 57, pp. 663-674, 2013.

[4] J. Mataix-Solera, A. Cerdà, V. Arcenegui, A. Jordán, and L. M. Zavala, "Fire effects on soil aggregation: a review," Earth-Science Reviews, vol. 109, no. 1-2, pp. 44-60, 2011.

[5] F. Oris, H. Asselin, A. A. Ali, W. Finsinger, and Y. Bergeron, "Effect of increased fire activity on global warming in the boreal forest," Environmental Reviews, vol. 22, no. 3, pp. 206-219, 2014.

[6] A. A. Dymov and D. N. Gabov, "Pyrogenic alterations of podzols at the North-east European part of Russia: morphology, 
carbon pools, PAH content," Geoderma, vol. 241-242, pp. 230237, 2015.

[7] E. A. Zharikova, "Post pyrogenic transformation of soil of Lower Amur region," Agroecology, vol. 8, pp. 57-60, 2015.

[8] E. Maksimova and E. Abakumov, "Wildfire effects on ash composition and biological properties of soils in forest-steppe ecosystems of Russia," Environmental Earth Sciences, vol. 74, no. 5, pp. 4395-4405, 2015.

[9] L. A. Michelotti and J. R. Miesel, "Source material and concentration of wildfire-produced pyrogenic carbon influence postfire soil nutrient dynamics," Forests, vol. 6, no. 4, pp. 1325-1342, 2015.

[10] E. Maksimova and E. Abakumov, "Micromorphological characteristics of sandy forest soils recently impacted by wildfires in Russia," Solid Earth, vol. 8, no. 2, pp. 553-560, 2017.

[11] E. Y. Maksimova, A. G. Kudinova, and E. V. Abakumov, "Functional activity of soil microbial communities in post-fire pine stands of Tolyatti, Samara oblast," Eurasian Soil Science, vol. 50, no. 2, pp. 239-245, 2017.

[12] B. R. Goforth, R. C. Graham, K. R. Hubbert, C. W. Zanner, and R. A. Minnich, "Spatial distribution and properties of ash and thermally altered soils after high-severity forest fire, southern California," International Journal of Wildland Fire, vol. 14, no. 4, pp. 343-354, 2005.

[13] X. Úbeda, P. Pereira, L. Outeiro, and D. A. Martin, "Effects of fire temperature on the physical and chemical characteristics of the ash from two plots of cork oak (Quercus Suber)," Land Degradation and Development, vol. 20, no. 6, pp. 589-608, 2009.

[14] P. Pereira, X. Úbeda, and D. A. Martin, "Fire severity effects on ash chemical composition and water-extractable elements," Geoderma, vol. 191, pp. 105-114, 2012.

[15] P. Pereira, A. Cerdà, X. Úbeda et al., "Spatial models for monitoring the spatio-temporal evolution of ashes after fire-a case study of a burnt grassland in Lithuania," Solid Earth, vol. 4, no. 1, pp. 153-165, 2013.

[16] M. B. Bodí, D. A. Martin, V. N. Balfour et al., "Wildland fire ash: production, composition and eco-hydro-geomorphic effects," Earth-Science Reviews, vol. 130, pp. 103-127, 2014.

[17] H. Knicker, "How does fire affect the nature and stability of soil organic nitrogen and carbon? A review," Biogeochemistry, vol. 85, no. 1, pp. 91-118, 2007.

[18] C. Wüthrich, D. Schaub, M. Weber, P. Marxer, and M. Conedera, "Soil respiration and soil microbial biomass after fire in a sweet chestnut forest in southern Switzerland," Catena, vol. 48, no. 3, pp. 201-215, 2002.

[19] R. Guénon, M. Vennetier, N. Dupuy, S. Roussos, A. Pailler, and R. Gros, "Trends in recovery of mediterranean soil chemical properties and microbial activities after infrequent and frequent wildfires," Land Degradation and Development, vol. 24, no. 2, pp. 115-128, 2013.

[20] J. A. González-Pérez, F. J. González-Vila, G. Almendros, and H. Knicker, "The effect of fire on soil organic matter-a review," Environment International, vol. 30, no. 6, pp. 855-870, 2004.

[21] G. Certini, C. Nocentini, H. Knicker, P. Arfaioli, and C. Rumpel, "Wildfire effects on soil organic matter quantity and quality in two fire-prone Mediterranean pine forests," Geoderma, vol. 167168, pp. 148-155, 2011.

[22] H. Zhao, D. Q. Tong, Q. Lin, X. Lu, and G. Wang, "Effect of fires on soil organic carbon pool and mineralization in a Northeastern China wetland," Geoderma, vol. 189-190, pp. 532539, 2012 .
[23] G. Almendros, F. J. González-Vila, and F. Martin, "Fire-induced transformation of soil organic matter from an oak forest: an experimental approach to the effects of fire on humic substances," Soil Science, vol. 149, no. 3, pp. 158-168, 1990.

[24] S. P. Bergeron, R. L. Bradley, A. Munson, and W. Parsons, "Physico-chemical and functional characteristics of soil charcoal produced at five different temperatures," Soil Biology and Biochemistry, vol. 58, pp. 140-146, 2013.

[25] M. A. Alexis, C. Rumpel, H. Knicker et al., "Thermal alteration of organic matter during a shrubland fire: a field study," Organic Geochemistry, vol. 41, no. 7, pp. 690-697, 2010.

[26] E. Gvozdetskiy, "Physical-geographical regionalization of the Tyumen region," Under the edition of Gvozdetskii N.A., M.: MGU, 1973. p. 246.

[27] "World reference base for soil resources. International soil classification system for naming soils and creating legends for soil maps," 2014. FAO. Rome, 2015.

[28] Wetlands of Moscow Region, Natural, economic and historicalcultural aspects, Wetland International-Russia Programme, KMK, Scientific Press, Tech. Rep., Moscow, Russia, p. 89, 2008.

[29] N. L. Kudravtseva, Geostructural location and conditions of peat bogs and deep lakes nourishment in Meshchera downfold and on the Oka-Tsna bar, The Aspects of ground water and engineergeological processes studying, Moscow, Russia, 1973.

[30] N. T. Zonov and A. E. Konstantinovitch, Geologic structure, mineral resources and ground waters of Egorievskii, Shaturskii, Korobovskii and Kurovskii Districts of Moscow Region, vol. 11, Transactions of Moscow Geological Survey Bureau, Moscow, Russia, 1932.

[31] A. Timashev, Shatura Power Plant, Moscow, Russia, 1932.

[32] F. R. Zaidel'man, D. I. Morozova, and A. P. Shvarov, "Changes in the properties of pyrogenic formations and vegetation on burnt previously drained peat soils of poles'ie landscapes," Eurasian Soil Science, vol. 36, no. 11, pp. 1159-1167, 2003.

[33] A. Van Donkelaar, R. V. Martin, R. C. Levy et al., "Satellite-based estimates of ground-level fine particulate matter during extreme events: a case study of the Moscow fires in 2010," Atmospheric Environment, vol. 45, no. 34, pp. 6225-6232, 2011.

[34] A. Z. Shvidenko, D. G. Shchepashchenko, E. A. Vaganov et al., "Impact of wildfire in Russia between 1998-2010 on ecosystems and the global carbon budget," Doklady Earth Sciences, vol. 441, part 2, pp. 1678-1682, 2011.

[35] E. V. Abakumov and E. I. Gagarina, The Soils of Samara Luka: Diversity, Genesis, Protection, St. Petersburg State University, St. Petersburg, Russia, 2008.

[36] E. V. Abakumov, N. Fujitake, and T. Kosaki, "Humus and Humic Acids of Luvisol and Cambisol of Jiguli Ridges, Samara Region, Russia," Applied and Environmental Soil Science, vol. 2009, Article ID 671359, 5 pages, 2009.

[37] V. A. Nosin, Soils of Kujbyshev Region, OGIZ, Kujbyshev, Russia, 1949.

[38] I. S. Urusevskaja, J. L. Meshalkina, and O. S. Hohlova, "Geographic and genetic features of Luvisols' humus status," Eurasian Soil Science, vol. 11, pp. 1377-1390, 2000.

[39] D. I. Vasil'eva and M. N. Baranova, Natural Resources of Samara Region, Samara municipal management institute, Samara, Russia, 2007.

[40] L. A. Vorobyova, Theory and Practice of the Chemical Soil Analysis, GEOS, Moscow, Russia, 2006.

[41] J. P. E. Anderson, "Soil respiration. Methods of Soil Analysis," in Chemical and Microbiological Properties, R. H. Miller, Ed., part 
2, pp. 831-871, American Society of Agronomy, Madison, WI, USA, 1982.

[42] M. B. Bodí, S. H. Doerr, A. Cerdà, and J. Mataix-Solera, "Hydrological effects of a layer of vegetation ash on underlying wettable and water repellent soil," Geoderma, vol. 191, pp. 14-23, 2012.

[43] S. W. Woods and V. N. Balfour, "The effects of soil texture and ash thickness on the post-fire hydrological response from ashcovered soils," Journal of Hydrology, vol. 393, no. 3-4, pp. 274286, 2010.

[44] J. León, M. B. Bodí, A. Cerdà, and D. Badía, “The contrasted response of ash to wetting. The effects of ash type, thickness and rainfall events.", Geoderma, vol. 209-210, pp. 143-152, 2013.

[45] P. Pereira, X. Úbeda, L. Outeiro, and D. Martin, "Factor analysis applied to fire temperature effects on water quality," in Forest Fires: Detection, Suppression and Prevention, E. Gomez and K. Alvarez, Eds., Series Natural Disaster Research, Prediction and Mitigation, pp. 273-285, Nova Science Publishers, New York, NY, USA, 2009.

[46] P. Pereira, A. Cerdà, X. Úbeda, J. Mataix-Solera, V. Arcenegui, and L. M. Zavala, "Modelling the impacts of wildfire on ash thickness in a short-term period," Land Degradation and Development, vol. 26, no. 2, pp. 180-192, 2013.

[47] E. Ejarque and E. Abakumov, "Stability and biodegradability of organic matter from Arctic soils of Western Siberia: insights from ${ }^{13}$ C-NMR spectroscopy and elemental analysis," Solid Earth, vol. 7, no. 1, pp. 153-165, 2016.

[48] N. T. Roulet, "Peatlands, carbon storage, greenhouse gases, and the kyoto protocol: prospects and significance for Canada," Wetlands, vol. 20, no. 4, pp. 605-615, 2000.

[49] D. G. Zamolodchikov, A. I. Utkin, G. N. Korovin, and O. V. Chestnykh, "Dynamics of carbon pools and fluxes in Russia's forest lands," Russian Journal of Ecology, vol. 36, no. 5, pp. 291301, 2005.

[50] V. L. Gavrikov, R. A. Sharafutdinov, A. A. Knorre et al., "How much carbon can the Siberian boreal taiga store: a case study of partitioning among the above-ground and soil pools," Journal of Forestry Research, vol. 27, no. 4, pp. 907-912, 2016.

[51] E. Y. Maksimova, A. S. Tsibart, and E. V. Abakumov, "Soil properties in the Tol'yatti pine forest after the 2010 catastrophic wildfires," Eurasian Soil Science, vol. 47, no. 9, pp. 940-951, 2014. 

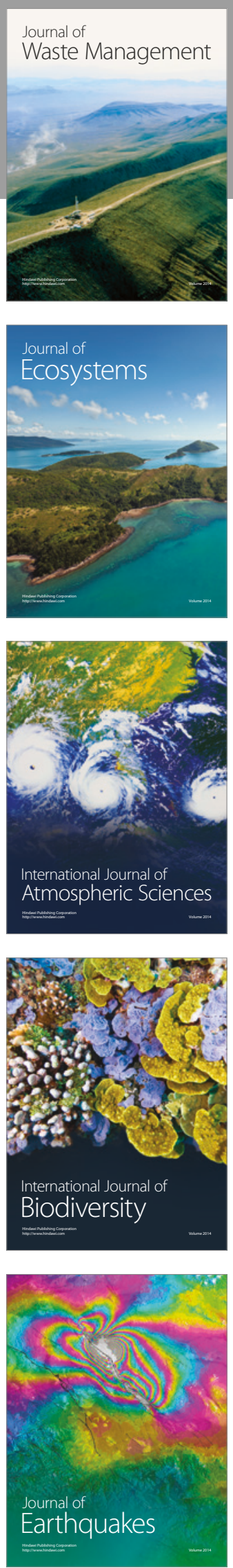
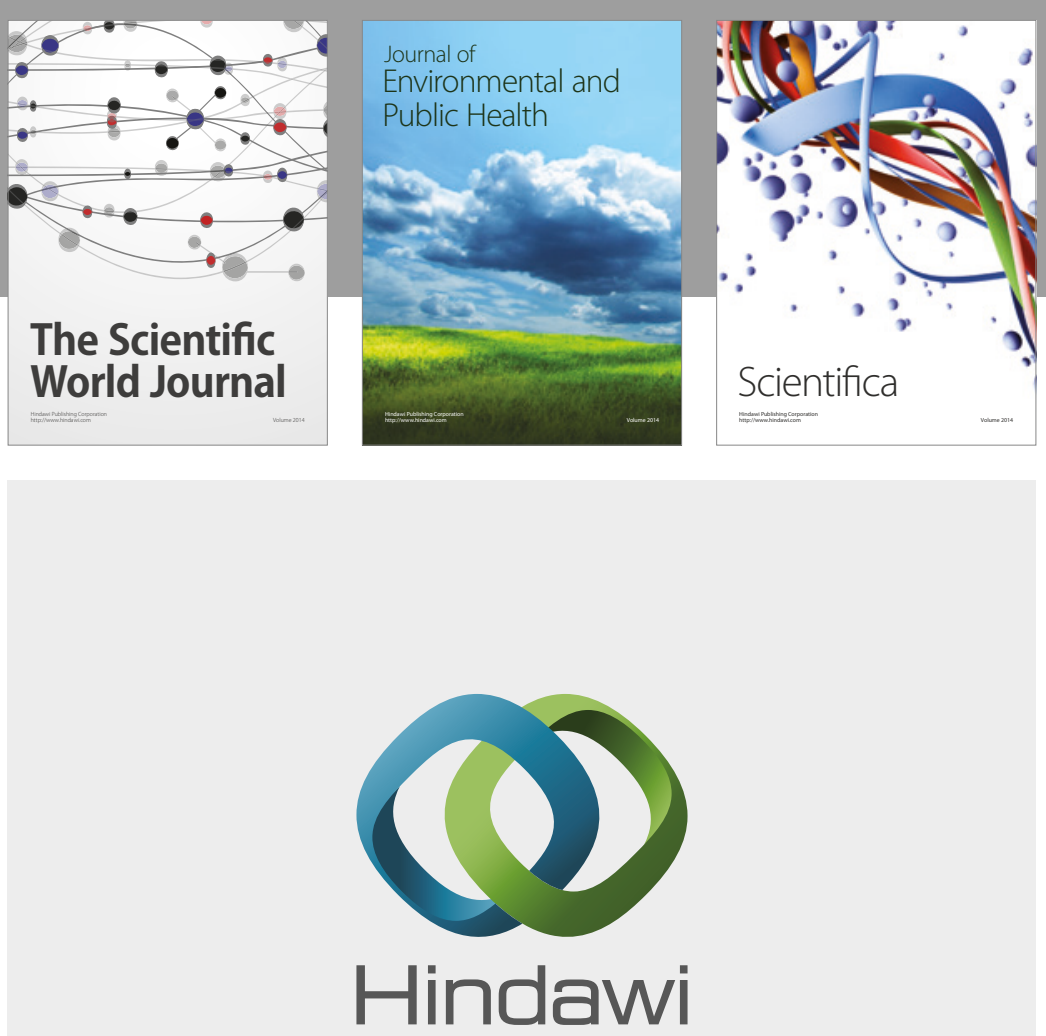

Submit your manuscripts at

https://www.hindawi.com
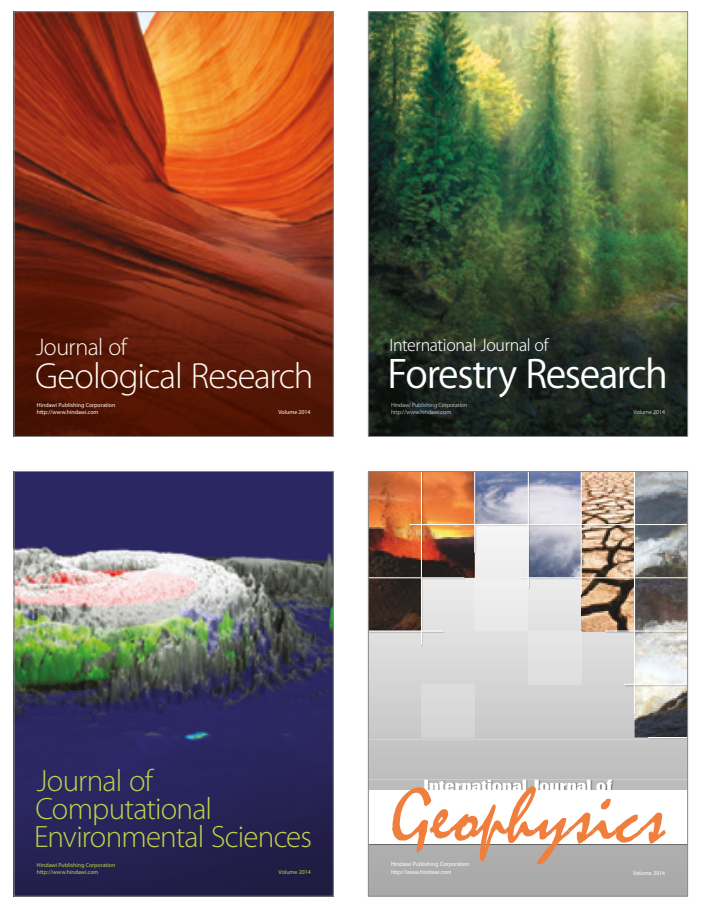
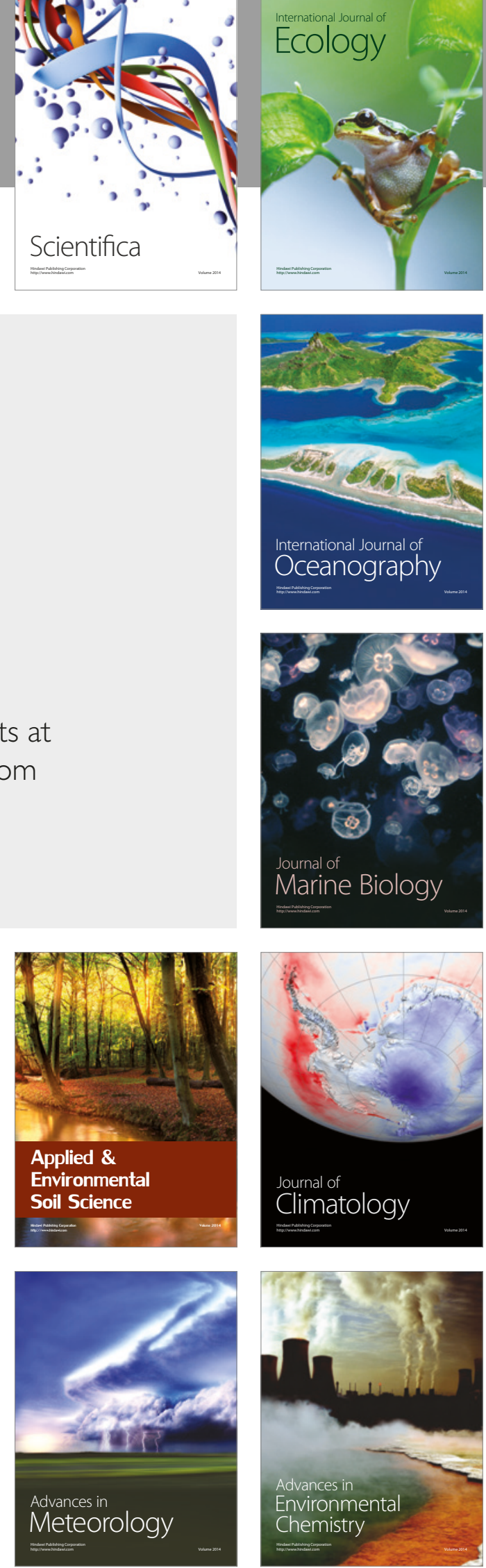